\title{
Acute and Chronic Effects of Amiodarone on Mammalian Ventricular Cells
}

\author{
Itsuo Kodama, MD, Kaichiro Kamtya, MD, \\ Haruo Honjo, MD, \\ and Junji TOYama, MD
}

\begin{abstract}
SumMary
This article reviews experimental studies on the electrophysiological effects of amiodarone on mammalian hearts. Acute application of amiodarone $\langle 0.1-10 \mu \mathrm{M})$ to papillary muscles or single ventricular cells isolated from rabbits or guinea pigs caused a significant decrease in action potential duration (APD) as well as a marked use-dependent inhibition of the maximum upstroke velocity (Vmax) of action potential with fast recovery kinetics. Acute amiodarone also caused a concentration-dependent decrease in the calcium current $\left(\mathbf{I}_{\mathrm{C} a}\right)$ and the delayed-rectifier potassium current $\left(\mathrm{I}_{\mathrm{K}}\right)$. Action potentials recorded from papillary muscles or single ventricular cells isolated from the rabbits treated with oral amiodarone $(100 \mathrm{mg} / \mathrm{kg}$ daily, 4 weeks) were characterized by a moderate frequency-independent prolongation of APD. There was no use-dependent $\dot{V} \max$ inhibition. The ventricular cells treated with chronic amiodarone showed a significant decrease in the current density of $I_{\mathrm{Ca}}, \mathrm{I}_{\mathrm{K}}$ and $\mathrm{I}_{\mathrm{to}}$. The amount of mRNA for $\mathrm{Kvl}$.5, a Shaker-related potassium channel from the rats treated with chronic oral amiodarone was significantly lower than that from control rats. These results suggest that the major and consistent effects of chronic amiodarone is repolarization delay (Class III action) through a decrease in $I_{K}$ and $I_{\text {to }}$ density, probably due to a modulation of gene expression of potassium channels. When amiodarone above a certain concentration is present in the extracellular space, fast kinetic Class I and Class IV actions would be added as acute effects. (Jpn Heart J 1996; 37: 719-730)
\end{abstract}

Key words: Action potential duration $\dot{V} \max$ Calcium current Delayed rectifier potassium current Transient outward current Kvl.5 mRNA

NTIARRHYTHMIC compounds, which delay repolarization of the
cardiacaction potential (Class III drugs) are now attracting a great deal of
attention as candidates to replace Class I drugs in the treatment of life-threaten-
ing ventricular tachyarrhythmias because they do not inhibit excitability, conduc-

From the Departments of Circulation and Humoral Regulation, Research Institute of Environmental Medicine, Nagoya University, Nagoya, Japan.

Address for correspondence: Itsuo Kodama, MD, Department of Humoral Regulation, Research Institute of Environmental Medicine, Nagoya University, Furo-cho, Chikusa-ku, Nagoya 464-01, Japan. 
tivity or contractility of normal cardiac muscle. Many new Class III compounds have been developed during the past several years. The usefulness of such new Class III drugs is, however, limited by different shortcomings; they often produce a particular type of polymorphic ventricular tachycardia, Torsade de pointes (Tdp). ${ }^{1)}$ The clinical incidence of Tdp for sotalol, clofilium and several newly developed Class III drugs was found to be $3-10 \%$, whereas the incidence for chronic amiodarone is unexpectedly low $(<0.1 \%) .{ }^{17}$ At present therefore, amiodarone, despite its undesirable extracardiac side effects, is believed to be more useful than any other Class III action drugs in terms of the balance of antiarrhythmic potency and proarrhythmic propensity. ${ }^{\text {l) }}$

Amiodarone has long been referred to as a prototype Class III antiarrhythmic agent because it prolongs both the action potential duration (APD) and the refractory period of cardiac muscle when administered chronically. ${ }^{2)}$ Many studies during the past decade have shown that the pharmacological actions of this compound are very complex. For instance, it possesses an inhibitory effect on the fast sodium channel as well as on the slow calcium channel., Amiodarone also has non-competitive antisympathetic effects and modulates thyroid function and phospholipid metabolism. ${ }^{5}$ ) Which action or combination of actions is fundamental and salutary for its potent antiarrhythmic activity is not known. Another interesting point concerning the profile of amiodarone is the difference between its acute and chronic effects. ${ }^{5)}$

In this article, we review experimental studies on the electrophysiological effects of amiodarone on single cells and multicellular tissue preparations isolated from mammalian hearts, and discuss the molecular and cellular modes of action of this unique antiarrhythmic agent.

\section{Acute Effects of Amiodarone}

Action potentials: The acute effects of amiodarone on action potential configuration were examined in single ventricular cells isolated from rabbit or guinea pig hearts ${ }^{6,7)}$ and in right ventricular papillary muscles isolated from rabbit hearts. ${ }^{8)}$ In single ventricular cells, $1-10 \mu \mathrm{M}$ amiodarone decreased the maximum upstroke velocity $(\dot{V} \max )$ and shortened the action potential duration (APD) in a concentration-dependent manner. Figure 1 shows the results of experiments in rabbit ventricular cells constantly stimulated at $1.0 \mathrm{~Hz}$. The mean decrease in $\dot{V} \max$ was $7 \%$ at $1 \mu \mathrm{M}$ and $13 \%$ at $10 \mu \mathrm{M}(n=5)$. APD was shortened by $9-33 \%$, whereas resting potential and amplitude of the action potential were unaffected. Qualitatively similar concentration-dependent decreases in $\dot{V} \max$ and APD shortening were observed in experiments using rabbit papillary muscle. 


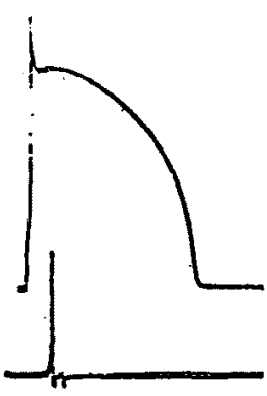

Control

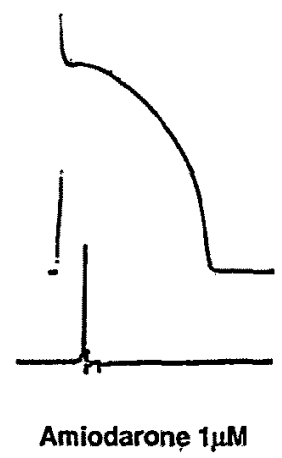

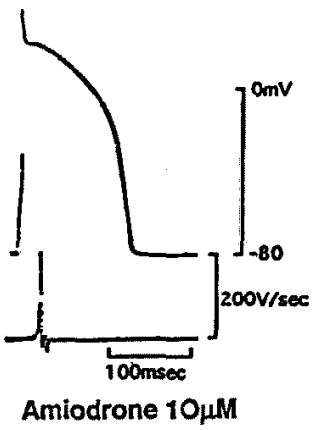

Figure 1. Acute effects of amiodarone on transmembrane action potentials. Action potentials (upper traces) and their first derivatives indicating the maximum upstroke velocity (V $\dot{V}_{\max }$, lower traces) were recorded from a single rabbit ventricular cell before (control) and 10 min after application of amiodarone (From Ref, 7 with permission).

The $\dot{V} \max$ inhibition of acute amiodarone was enhanced at higher stimulation frequencies. The use-dependent $\dot{V}$ max inhibition following a long rest period was observed with stimulation trains of $>0.5 \mathrm{~Hz}$. The recovery time constant from the use-dependent inhibition of $\dot{V} \max$ was $404 \pm 15 \mathrm{msec}(n=5)$ in experiments using guinea pig ventricular myocytes. ${ }^{6}$ Similar values $(452 \mathrm{msec})$ were obtained in experiments using rabbit papillary muscles. ${ }^{8)}$

These results are consistent with previous reports by other investigators in ventricular muscles and Purkinje fibers from dogs and guinea pigs, $, 3,9,10)$ and suggest that acute amiodarone, like Class I antiarrhythmic drugs, blocks the sodium channel in a use-dependent manner. More direct evidence of sodium channel block by acute amiodarone was presented in voltage-clamp experiments in single Purkinje and ventricular cells, ${ }^{11)}$ and in single channel recording in cultured cardiocytes of neonatal rats. ${ }^{12}$

Figure 2 presents the results of experiments in guinea pig ventricular cells to test the state-dependence of sodium channel block by acute amiodarone. ${ }^{6)}$ The single pipette wholc-cell clamp method was used to control and record membrane potentials. Following a rest period of $30 \mathrm{sec}$, the membrane potential was clamped from the holding level at $-82 \mathrm{mV}$ up to $0 \mathrm{mV}$ for 10 to $1,000 \mathrm{msec}$. At the end of the conditioning clamp, the potentials were clamped back to the resting level again for $100 \mathrm{msec}$. The voltage-clamp was then released to elicit the test action potential (100 msec is long enough for a drug-free channel to reactivate fully, but short enough so that only partial dissociation of the drug from the blocked channel occurs). The $\dot{V} \max$ of the test action potential was measured as an index of sodium channel availability. In untreated cells, a single conditioning clamp up to $0 \mathrm{mV}$ caused only a slight decrease in $\dot{V} \max$ reflecting "slow inactivation" of the sodium channel; while the $\dot{V} \max$ following a $1,000 \mathrm{msec} 0 \mathrm{mV}$ 


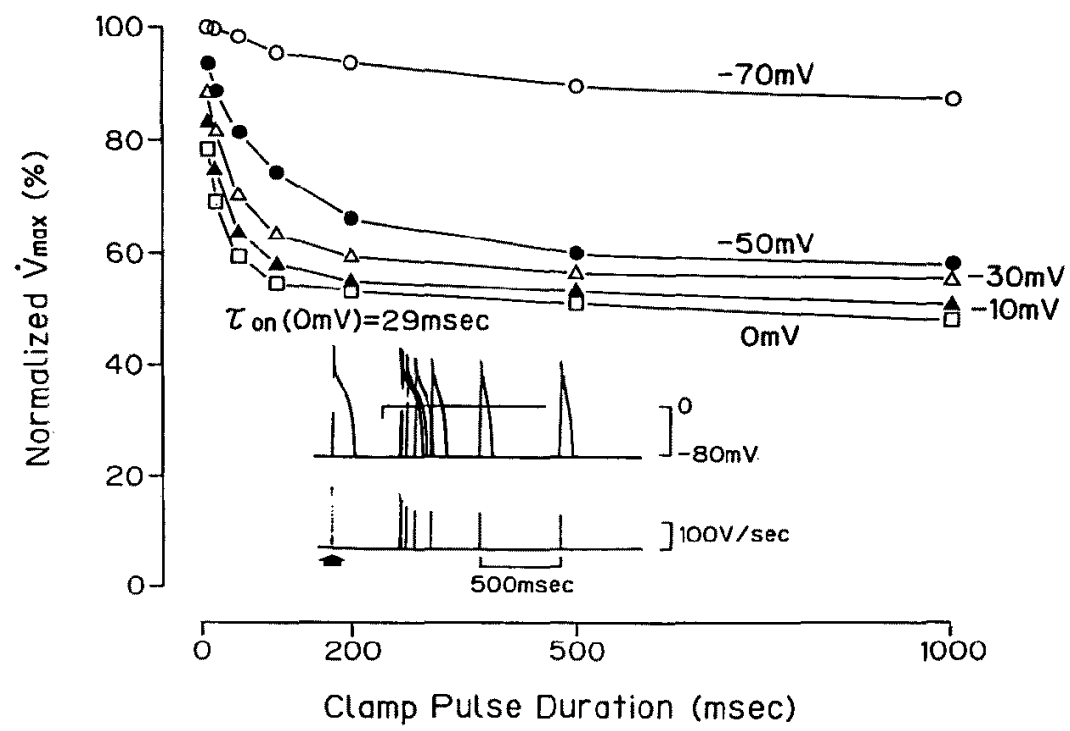

Figure 2. Influence of conditioning depolarization on V $\max$ inhibition by acute amiodarone. Inset shows superimposed action potentials (upper traces) and their differentiated upstroke spikes (lower traces). Action potentials were elicited without clamp pulses as a reference level (left end) or $100 \mathrm{msec}$ after a conditioning clamp to - 70 $0 \mathrm{mV}$ for 10 to $1,000 \mathrm{msec}$. Each conditioning depolarization was preceded by a $30 \mathrm{sec}$ rest period. The records were obtained 20 min after application of amiodarone $(1 \mu \mathrm{M})$. In the graph, $\dot{V} \max$ of test action potential normalized to the reference level was plotted against the conditioning clamp pulse duration. The time constant $\left(\tau_{\text {on }}\right)$ for the exponential decay of $\dot{V} \max$ at $0 \mathrm{mV}$ conditioning depolarization was $29 \mathrm{msec}$. (From Ref. 6 with permission).

clamp was decreased by an average of $6.1 \%$. After treatment with $1 \mu \mathrm{M}$ amiodarone for $20 \mathrm{~min}$, similar clamp pulses caused much greater $\dot{V}$ max reduction, which was dependent on the duration and voltage of the plateau clamp. The $\dot{V} \max$ decay with prolongation of the conditioning clamp to $0 \mathrm{mV}$ corresponded well to a single exponential function with a time constant of $29 \mathrm{msec}$. Such exponential $\dot{V} \max$ decay was induced by a conditioning clamp to a level more positive than $-70 \mathrm{mV}$, and its extent reached a maximal plateau at about $-10 \mathrm{mV}$.

Most of the sodium channel is in the resting state at the holding potential of $-82 \mathrm{mV}$. On the upstroke phase of the clamp pulse, the sodium channel is switched from the resting to the activated state. Within several milliseconds, the channel is fully inactivated, and this inactivated state lasts throughout the subsequent plateau phase. Upon repolarization, the sodium channel returns to the resting state. The $\dot{V} \max$ changes in Figure 2 may, therefore, indicate that amiodarone blocks the sodium channel primarily when it is in the inactivated state.

Ionic currents: We measured L-type calcium current $\left(\mathrm{I}_{\mathrm{Ca}}\right)$, delayed rectifier 
potassium current $\left(\mathrm{I}_{\mathrm{K}}\right)$ and transient outward current $\left(\mathbf{I}_{\mathrm{t}}\right)$ in whole-cell voltageclamp experiments using single rabbit ventricular cells. ${ }^{7}$ In experiments to record $\mathrm{I}_{\mathrm{Ca}}$, potassium in the external and pipette solutions was replaced with cesium, and depolarizing pulses were applied at $0.1 \mathrm{~Hz}$ from a holding potential at $-40 \mathrm{mV}$. $10 \mu \mathrm{M}$ amiodarone caused a significant reduction in $\mathrm{I}_{\mathrm{Ca}}$ without affecting its voltage-dependence. The $\mathrm{I}_{\mathrm{Ca}}$ amplitude at $0 \mathrm{mV}$ was decreased by $18-27 \%$ $(n=4)$. These results are consistent with previous reports by Nishimura et al ${ }^{13)}$ and Valenzuela \& Benett. ${ }^{14 ;}$

$\mathrm{I}_{\mathrm{K}}$ was recorded in $\mathrm{Na}^{+}$- and $\mathrm{K}^{+}$-free external solution containing $3 \mu \mathrm{M}$ nisoldipine to isolate the current. Three sec depolarizing pulses were applied from the holding potential at $-50 \mathrm{mV}$ at $30 \mathrm{sec}$ intervals. $\mathrm{I}_{\mathrm{K} \text {,tail }}$ was measured on the repolarization back to the holding potential. Amiodarone $(1-10 \mu \mathrm{M})$ decreased $I_{K}$ in a concentration-dependent manner. The amplitude of $I_{K, \text { tail }}$ following $0 \mathrm{mV}$ depolarization was decreased, on average by $22 \%$ at $1 \mu \mathrm{M}$ and by $51 \%$ at $10 \mu \mathrm{M}$ amiodarone $(n=6){ }^{\text {.7) }}$ The delayed rectifier current is now subdivided into at least two components, $I_{K, \text { slow }}\left(I_{K, s}\right)$ and $I_{K}$,rapid $\left(I_{K, r}\right) \cdot{ }^{15\rangle}$ In rabbit ventricular cells, $\mathrm{I}_{\mathrm{K}, \mathrm{r}}$ is the prominent component. ${ }^{15)}$ Our data, therefore, indicate a substantial inhibition of $\mathrm{I}_{\mathrm{K}, \mathrm{r}}$ by acute amiodarone. It has been demonstrated by Balser et al ${ }^{16)}$ that acute amiodarone blocks $I_{K}$ in guinea pig ventricular cells in which $I_{K, s}$ is more prominent than $\mathrm{I}_{\mathrm{K}, \mathrm{r}}$.

In experiments to measure $\mathrm{I}_{\mathrm{t}}$, external solution containing $2 \mathrm{mM} \mathrm{CoCl} \mathrm{C}_{2}$ and $10 \mu \mathrm{M}$ TTX was used to block $\mathrm{I}_{\mathrm{Ca}}$ and $\mathrm{I}_{\mathrm{N}_{\mathrm{a}}}$, and depolarizing pulses for 300 msec were applied at $0.1 \mathrm{~Hz}$ from a holding potential at $-80 \mathrm{mV}$. Amiodarone up to $10 \mu \mathrm{M}$ did not affect $\left.\mathbf{I}_{\text {to }}{ }^{7}\right)$ The inward rectifier current $\left(\mathbf{I}_{\mathbf{K} 1}\right)$ was also unaffected by acute amiodarone.?

Thus, acute amiodarone inhibited not only the sodium and calcium inward currents but also the potassium outward currents. Previous reports on the acute effects of amiodarone on APD of cardiac muscle are conflicting. ${ }^{4)}$ Some studies have shown minimal to moderate APD prolongation, while others no APD prolongation, like our data in rabbit ventricular cells. This discrepancy may be explained by different ionic currents that are responsible for the repolarization of action potentials in different animal species and in different cardiac tissues. An inhibition of inward currents would shorten APD, while a greater inhibition of outward currents would prolong it. Recently, Nakaya et al have shown that acute amiodarone also blocks ligand-gated potassium channels. ${ }^{17)}$

\section{Chronic Effects of Amiodarone}

Action potentials: We studied the chronic effects of amiodarone in rabbits $(1.8-2.2 \mathrm{~kg})$ in a series of experiments. ${ }^{7,8,18)}$ The animals were treated for 4 weeks 
Control
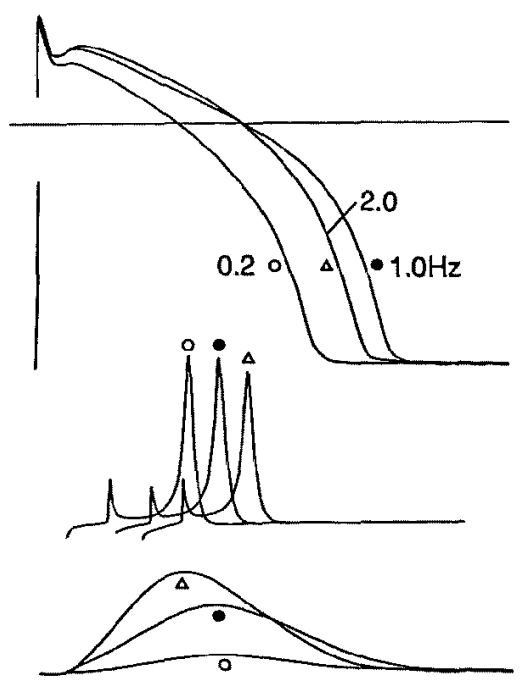

Amiodarone

(100mg/kg)
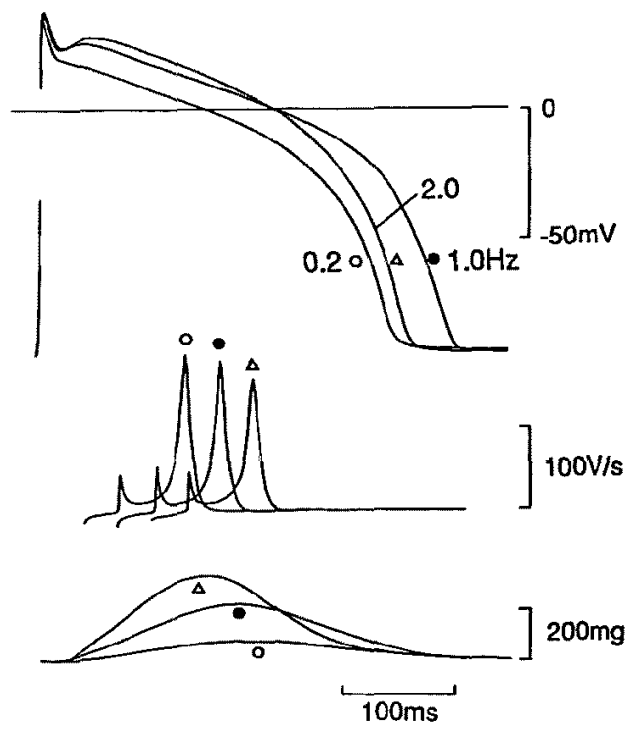

Figure 3. Effects of chronic amiodarone on the transmembrane action potential and contraction of rabbit papillary muscles. The preparations from an untreated rabbit and a rabbit treated with amiodarone $(100 \mathrm{mg} / \mathrm{kg} /$ day $)$ were stimulated at $0.1 \mathrm{~Hz}(\mathrm{O})$, $1.0 \mathrm{~Hz}()_{)}$and $3.0 \mathrm{~Hz}(\Delta)$. The differentiated upstroke spikes (Vmax) of the action potential (middle) traces were recorded at a faster sweep velocity. (From Ref. 8 with permission).

with oral amiodarone at doses ranging from 20 to $100 \mathrm{mg} / \mathrm{kg}$ daily. On the last day of drug treatment, peripheral blood was sampled to measure serum amiodarone and the ECGs of extremity leads were recorded. The rabbits were then sacrificed to obtain right ventricular papillary muscles or single ventricular cells through enzyme digestion. Untreated rabbits of corresponding weight were used as controls. EGGs were not affected at a daily dose of $20 \mathrm{mg} / \mathrm{kg}$ amiodarone. In rabbits that received 50 or $100 \mathrm{mg} / \mathrm{kg}$ amiodarone per day, the $\mathrm{RR}, \mathrm{QT}$ and corrected $\mathrm{QT}\left(\mathrm{QT}_{\mathrm{c}}\right)$ intervals were significantly prolonged in comparison with controls. PQ and QRS remained unchanged. ${ }^{8}$ Serum and myocardial tissue amiodarone concentrations in rabbits that received 50 or $100 \mathrm{mg} / \mathrm{kg}$ of amiodarone per day were $0.14-0.18 \mu \mathrm{g} / \mathrm{m} l$ and $1.47-3.63 \mu \mathrm{g} / \mathrm{g}$ wet weight, respectively. ${ }^{3)}$

Figure 3 presents the action potentials and contractions of papillary muscles in control and amiodarone-treated rabbits. ${ }^{8)}$ The records at three stimulation rates $(0.2 \mathrm{~Hz}, 1.0 \mathrm{~Hz}$, and $2.0 \mathrm{~Hz})$ have been superimposed. Muscle treated with amiodarone $(100 \mathrm{mg} / \mathrm{kg}$, daily) had longer APD than controls at all stimulation frequencies. A slight decrease in contractile force was also observed. Action po- 
Table. Effects of Ghronic Oral Amiodarone on Transmembrane Action Potential and Contraction in Rabbit Papillary Muscle

\begin{tabular}{lcccccc}
\hline & $(n)$ & $\begin{array}{c}\text { RP } \\
(\mathrm{mV})\end{array}$ & $\begin{array}{c}\text { AMP } \\
(\mathrm{mV})\end{array}$ & $\begin{array}{c}\dot{\text { Vmax }}(\mathrm{V} / \mathrm{S}) \\
\text { Control }\end{array}$ & $\begin{array}{c}\text { APD-70 mV } \\
(\mathrm{msec})\end{array}$ & $\begin{array}{c}\text { DT } \\
(\mathrm{mg})\end{array}$ \\
$\begin{array}{l}\text { Amiodarone } \\
\quad(15)\end{array}$ & $-88 \pm \mathrm{I}$ & $120 \pm 2$ & $209 \pm 11$ & $277 \pm 7$ & $288 \pm 41$ \\
$\quad 100 \mathrm{mg} / \mathrm{kg} / \mathrm{day}$ & $(8)$ & $-90 \pm 1$ & $121 \pm 2$ & $196 \pm 6$ & $312 \pm 8^{*}$ & $218 \pm 32$ \\
& $(6)$ & $-87 \pm 1$ & $119 \pm 1$ & $172 \pm 8^{*}$ & $333 \pm 6^{*}$ & $207 \pm 29^{*}$ \\
\hline
\end{tabular}

Values are means $\pm \mathrm{SE} n=$ number of rabbits. Oral amiodarone was administered at a dose of 50 or $100 \mathrm{mg} / \mathrm{kg} /$ day for 4 weeks. $\mathrm{RP}=$ resting membrane potential; $\mathrm{AMP}=$ amplitude of action potential; $\dot{V} \max =$ the maximum upstroke velocity of action potential; $\mathrm{APD}-70 \mathrm{mV}=$ action potential duration at -70 $\mathrm{mV} ; \mathrm{DT}=$ peak developed tension. Significantly different from control at ${ }^{*} p<0.05$.

tential parameters during constant stimulation at $1.0 \mathrm{~Hz}$ are summarized in the Table. In muscles treated with 50 or $100 \mathrm{mg} / \mathrm{kg}$ daily amiodarone, APD at - 70 $\mathrm{mV}$ repolarization was prolonged by $13 \%$ and $20 \%$, respectively. At the higher dose, the $\dot{V} \max$ and developed tension were also slightly decreased.

Muscles treated with chronic amiodarone, like control muscles, did not exhibit use-dependent $\dot{V} \max$ inhibition in experiments where trains of stimulation $(0.5-3.0 \mathrm{~Hz})$ were applied following a long rest period. ${ }^{3)}$ This was also confirmed in single rabbit ventricular cells treated with chronic amiodarone.?

There is a considerable controversy among previous investigators regarding the Class I action of chronic amiodarone. Mason et al ${ }^{19}$ showed a marked usedependent $\dot{V} \max$ inhibition in guinea pig papillary muscles after chronic treatment with amiodarone. In support of this finding, Anderson et $\mathrm{al}^{20)}$ demonstrated a rate-dependent decrease in conduction velocity in the epicardium of dogs after chronic treatment with amiodarone. The use-dependent slowing of conduction in the His-Purkinje system has also been demonstrated in dogs treated with chronic amiodarone. ${ }^{21)}$ In contrast, Singh and colleagues showed minimal or no significant change in $\dot{V} \max$ in atrial and ventricular muscles from rabbits after longterm amiodarone treatment. ${ }^{4)}$ Gallagher et al $^{22)}$ showed that Purkinje fibers obtained from dogs after long-term amiodarone treatment did not show use-dependent $\dot{V} \max$ inhibition. Our data showing no use-dependent $\dot{V}$ max inhibition are in accordance with the latter group. This discrepancy may be attributable to the experimental conditions. For instance, serum and myocardial concentrations of amiodarone found in experiments conducted by Anderson et $\mathrm{al}^{20)}$ were several times higher than those found by others, including ourselves. Species and tissue differcnces in response to the chronic effects of amiodarone (and its active metabolite) might also play a role.

In control rabbit papillary muscles, APD was the longest at a stimulation frequency of $0.5 \mathrm{~Hz}$, shortening at both higher and lower frequencies, giving rise to a bell-shaped frequency-APD relationship. In muscles trcated with daily doses 

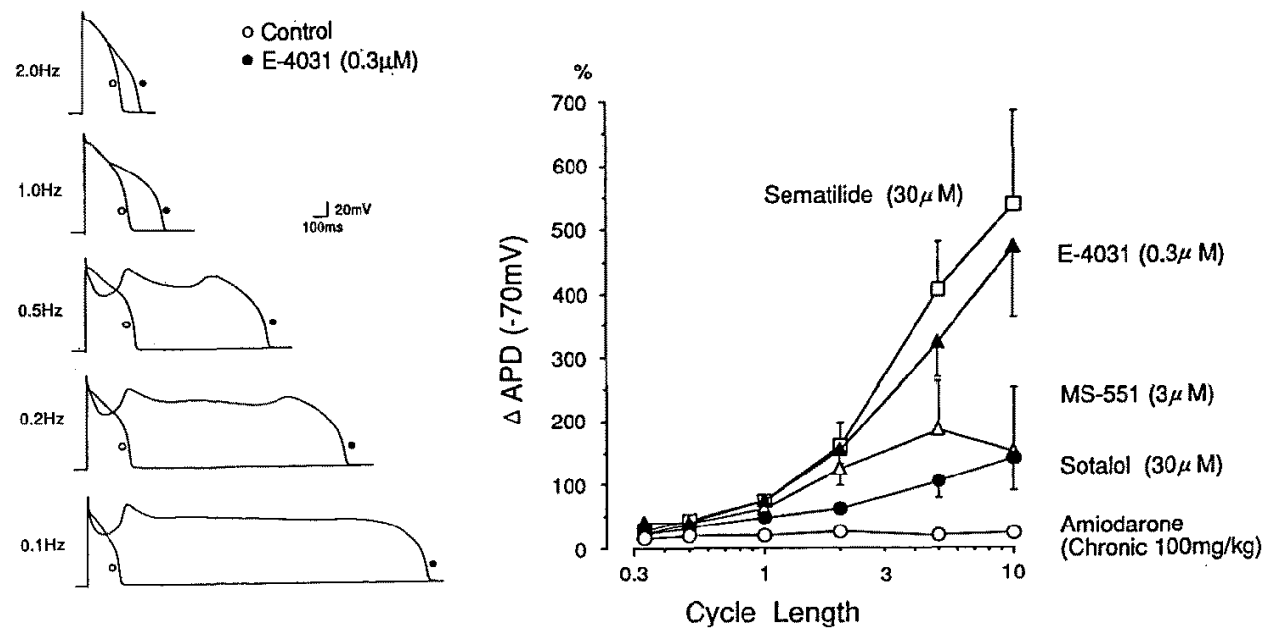

Figure 4. Frequency-dependence of APD prolongation by chronic amiodarone and by acute application of sematilide, E-4031, MS-551 or sotalol in rabbit papillary muscles. Left: superimposed action potentials from a preparation stimulated at $0.1 \sim$ $2.0 \mathrm{~Hz}$ before and after application of $\mathrm{E}-4031(0.3 \mu \mathrm{M})$. Right: percentage prolongation of APD at $-70 \mathrm{mV}$ repolarization by chronic amiodarone $(100 \mathrm{mg} / \mathrm{kg} / \mathrm{day}$, 4 weeks) and by acute application of sematilide $(30 \mu \mathrm{M})$, E-4031 $(0.3 \mu \mathrm{M})$, MS-551 $(3 \mu \mathrm{M})$ or sotalol $(30 \mu \mathrm{M})$ are plotted against cycle length of stimulation. Values are mean $\pm \mathrm{SE}$ $(\mathrm{N}=5-6)$.

of amiodarone of 50 or $100 \mathrm{mg} / \mathrm{kg}$, APD was prolonged over the entire range of frequencies from 0.1 to $3.0 \mathrm{~Hz}$. Percentage prolongation of APD at each frequency was more or less similar, and the bell-shaped relationship observed in control muscles was well preserved. ${ }^{8)}$

We compared the frequency-dependence of $\mathrm{APD}$ prolongation in rabbit papillary muscles due to chronic amiodarone with that due to the acute application of four compounds having Class III action; sematilide, sotalol, E-4031 and MS-551. Figure 4A presents the superimposed action potentials of papillary muscle before and after application of E-4031 $(0.3 \mu \mathrm{M})$ during stimulation at 0.1 to $2.0 \mathrm{~Hz}$. APD prolongation by E-4031 was progressively enhanced at lower frequencies. The oscillation of membrane potential, like early afterdepolarization, was induced at rates lower than $1.0 \mathrm{~Hz}$. Figure 4B illustrates the percentage prolongation of APD. APD prolongation by sematilide $(30 \mu \mathrm{M}), \mathrm{E}-4031(0.3 \mu \mathrm{M})$ and sotalol $(30 \mu \mathrm{M})$ was enhanced almost linearly at longer cycle lengths, resulting in a marked "reverse" frequency-dependence. The APD prolongation by MS-55l $(3 \mu \mathrm{M})$ was maximal at a cycle length of $5 \sec (0.2 \mathrm{~Hz})$, and decreased slightly at lower frequencies. In contrast with these four compounds, the frequency-dependence of APD prolongation by chronic amiodarone was minimal or negligible.

There is a general agreement between previous investigators that the 
chronic treatment of mammals with amiodarone for several weeks causes moderate prolongation of APD throughout the entire heart. ${ }^{3,4)}$ However, only limited information is available on the frequency-dependence of this Class III action. Anderson et $\mathrm{al}^{20)}$ demonstrated in dogs that repolarization intervals and refractory periods of epicardial ventricular muscle assessed by surface electrograms were prolonged to a similar extent over stimulation frequencies ranging from 1 to $5 \mathrm{~Hz}$. Our data in rabbit ventricular muscles ${ }^{8)}$ are consistent with their results. Such a frequency-independent Class III action of amiodarone (unlike other agents causing Class III action) may be important for its potent antiarrhythmic and minimal proarrhythmic activities.

Moderate APD prolongation by chronic amiodarone was also observed in single ventricular cells isolated from rabbit hearts. APD at $90 \%$ repolarization in the cells treated with $100 \mathrm{mg} / \mathrm{kg}$ of amiodarone per day $(n=17)$ was longer than that in control cells $(n=18$ ) by an average of $42 \%$, whereas other action potential parameters including $\dot{V} \max$ were unaffected. ${ }^{7)}$

Ionic currents: Ionic currents responsible for APD prolongation induced by chronic amiodarone were investigated in single ventricular cells isolated from rabbits untreated (control, $n=6-16)$ and treated $(n=6$ 9) with daily $100 \mathrm{mg} / \mathrm{kg}$ oral doses of amiodarone for 4 weeks. ${ }^{7)}$ L-type calcium current $\left(\mathrm{I}_{\mathrm{Ca}}\right)$, delayed rectifier potassium current $\left(\mathrm{I}_{\mathrm{K}}\right)$, 4AP-sensitive transient outward current $\left(\mathbf{I}_{\mathrm{to}}\right)$, and inward rectifier potassium current $\left(\mathrm{I}_{\mathrm{K}}\right)$ were recorded using a whole-cell voltage clamp technique in ventricular cells. Pulse protocols of voltage-clamp and the contents of external and pipette solutions were the same as described in the acute experiments. The current density was calculated from the cell capacitance.

In ventricular cells from amiodarone-treated rabbits, the current density of $\mathrm{I}_{\mathrm{Ca}}$ was significantly less (by 13-43\%) than control, but its voltage-dependence was unaffected. ${ }^{7)}$ The current densities of $\mathrm{I}_{\mathrm{K}, \text { tail }}$ and $\mathrm{I}_{10}$ were also decreased significantly from control (by $43-62 \%$ and $23-44 \%$, respectively) without any appreciable changes in their voltage-dependence. ${ }^{7)}$ In contrast, there was no significant difference in the current density of $I_{K 1}$ between control and amiodarone-treated cells. ${ }^{7)}$ These results suggest that APD prolongation induced by chronic amiodarone can be attributed mainly to an inhibition of $I_{K}$ and $I_{t o}$. The inhibition of $\mathrm{I}_{\mathrm{Ca}}$ is expected to counteract the excessive APD prolongation.

\section{Gene Expression of Potassium Ghannels}

In our last series of experiments, we investigated the exprcssion of Shakerrelated potassium channel genes in rats $^{23)}$ in order to obtain an insight into the molecular mechanism responsible for the reduction in potassium channel $\left(I_{K}, I_{00}\right)$ density due to chronic amiodarone administration. 
Male Wister rats (140-160 g) aged 6 weeks were treated for 4 weeks with oral amiodarone at a daily dose of $100 \mathrm{mg} / \mathrm{kg}$. The rats were then sacrificed to obtain blood samples and the ventricles. Total RNA was extracted by the standard AGPC method. Kv1.5 mRNA levels were measured by Northern blot analysis using densitometry of the autoradiogram. Glyceraldehyde phosphate dehydrogenase (GAPDH) mRNA levels were used as internal controls. cDNA for Kv1.5 was kindly donated by Dr. H. Mastubara (Kansai Medical School, Moriguchi, Osaka, Japan). A fragment (EcoRI-EcoRI) from $\mathrm{K}_{v} 1.5$ was used as a probe.

The mRNA for Kvl.5 was detected as a single band $(3.4 \mathrm{~Kb})$ in both the control $(n=7)$ and amiodarone-treated groups $(n=7)$. The molecular size of the band was consistent with that reported by Matsubara et al. ${ }^{24)}$ In the amiodaronetreated rats, the amount of Kv1.5 mRNA was less than the control by approximately $41 \%$, suggesting that gene expression of the Kv1.5 channel in the ventricle is modulated (down-regulated) by long-term treatment with amiodarone.

Recent molecular biological studies have shown that several (at least seven) distinct voltage-gated potassium channel genes are expressed in rat cardiac tissues ${ }^{25)}$ These include four Shaker-related (Kvl subfamily) genes; Kv1.1, Kv1.2, $\mathrm{Kv} 1.4$ and Kv1.5. The structural and functional relation of these cloned channels to the native potassium channels is still unclear. These channel gene products can form heteromeric potassium channels (hetero-tetramers) that exhibit current kinetics and pharmacological properties distinct from the original homomeric channels (homo-tetramers). Hence, the diversity of the native voltage-gated potassium currents in cardiac tissues could be due to the expression of multiple gene products that assemble in a variety of homomeric and heteromeric channels. Our Kv1.5 mRNA data indicate that chronic amiodarone administration can modulate the gene expression level for potassium channels. Nevertheless, further experimental studies are needed to clarify the exact molecular mode of the action of amiodarone to decrease the potassium current density.

\section{Conclusion}

Based on the experimental studies described above, the acute and chronic effects of amiodarone on the electrophysiological properties of mammalian ventricular muscle can be summarized as follows. 1) The acute effect of amiodarone is a lidocaine-like inhibitory action against sodium channels. It blocks the channels during the inactivated state with fast kinetics. 2) Acute amiodarone also blocks calcium currents $\left(\mathrm{I}_{\mathrm{Ca}}\right)$ and the delayed rectifier potassium current $\left(\mathrm{I}_{\mathrm{K}}\right)$. It does not prolong the APD of ventricular cells. 3) The major effect of chronic amiodarone is moderate APD prolongation with minimal frequency-dependence. 
The APD prolongation is most likely attributable to a decrease in the current density of $I_{K}$ and $I_{10}$. 4) Chronic amiodarone also decreases $I_{C a}$ density. This action would counteract the excessive APD prolongation. 5) Chronic amiodarone caused a down-regulation of ventricular Kv1.5 mRNA in rat hearts, suggesting a drug-induced modulation of potassium channel gene expression.

Our experiments to study the chronic effects of amiodarone were carried out using drug-free crystalloid solutions. In other words, unlike in-vivo experiments or clinical cases, the data were obtained with negligible extracellular levels of amiodarone. In patients receiving long term oral amiodarone, serum levels of the drug have a wide range, corresponding to 0.1 to $7.6 \mu \mathrm{M}^{8)}$ Accordingly, in individual cases of amiodarone therapy, the acute effects would be added to the chronic effects to varying degrees, depending on the serum levels of amiodarone.

\section{REFERENCES}

1. Singh BN. Controlling cardiac arrhythmias by lengthening repolarization: Historical overview. Am J Cardiol 1993; 72: 18F-24F.

2. Vaughan Williams EM. A classification of antiarrhythmic action reassessed after a decade of new drugs. J Clin Pharmacol 1984; 24: 129-47.

3. Mason JW. Amiodarone. N Engl J Med 1987; 316: 455-66.

4. Singh BN, Venkatesh N, Nademanee K, Josephson MA, Kannan R. The historical development, cellular electrophysiology and pharmacology of amiodarone. Prog Cardiovasc Dis 1989; 31: 249-80.

5. Singh BN. Amiodarone: Electropharmacologic properties. In: Vaughan Williams EM, editor. Antiarrhythmic Drugs Berlin: Springer-Verlag, 1990: 335-64.

6. Honjo H, Kodama I, Kamiya K, ToyamaJ. Block of cardiac sodium channels by amiodarone studied by using Vmax of action potential in single ventricular myocytes. Br J Pharmacol 1991; 102: 651-56.

7. Kamiya K, Cheng J, Kodama I, Toyama J. Acute and chronic effects of amiodarone on action potential and ionic currents in single rabbit ventricular myocytes. In: Toyama J, Hiraoka M, Kodama I, editors. Recent Progress in Electropharmacology of the Heart, Boca Raton: CRC Press, 1996: 139-49.

8. Kodama I, Suzuki R, Kamiya K, Iwata H, Toyama J. Effects of long-term oral administration of amiodarone on the electromechanical performance of rabbit ventricular muscle. Br J Pharmacol 1992; 107: $502-9$.

9. Pallandi RT, Campbell TJ. Resting and rate-dependent depression of V́max of guinca-pig ventricular action potentials by amiodarone and desethylamiodarone. $\mathrm{Br} \mathrm{J}$ Pharmacol 1987; 92: 97-103.

10. Varro A, Nakaya Y, Elharrar V, Surawicz B. Use-dependent effects of amiodarone on Vmax in cardiac Purkinje and ventricular muscle fibers. Eur J Pharmacol 1985; 112: 419-22.

11. Follmer $\mathrm{CH}$, Aomine $\mathrm{M}$, Yeh JZ, Singer $\mathrm{DH}$. Amiodarone-induced block of sodium current in isolated cardiac cells. J Pharmacol Exp Ther 1987; 243; 187-94.

12. Kohlhardt M, Fichtner $\mathrm{H}$. Block of single cardiac $\mathrm{Na}^{+}$channels by antiarrhythmic drugs: The effect of amiodarone, propafenone and diprafenone. J Membr Biol 1988; 102: 105-19.

13. Nishimura $\mathrm{M}$, Follmer $\mathrm{CH}$, Singer $\mathrm{DH}$. Amiodarone blocks calcium current in single guinea pig ventricular myocytes. J Pharmacol Exp Ther 1989; 252: 650-9.

14. Valenzuela G, Benett PB. Voltage- and use-dependent modulation of calcium channel current in guinea pig ventricular cells by amiodarone and des-oxo-amiodarone. J Cardiovasc Pharmacol 1991; 17: $894-902$.

15. Sanguinetti MC. Modulation of potassium channels by antiarrhythmic and antihypertensive drugs. Hypertension 1992; 19: 228-36.

16. Balser JR, Benett PB, Hondeghem LM, Roden DM. Suppression of time-dependent outward current 
in guinea pig ventricular myocytes. Actions of quinidine and amiodarone. Circ Res 1991; 69: 519-29.

17. Mori K, Saito T, Masuda Y, Nakaya $\mathrm{H}$. Effects of class III antiarrhythmic drugs on the $\mathrm{Na}^{+}$- activated $\mathrm{K}^{+}$channels in guinea pig ventricular cells. Br J Pharmacol 1996 (in press).

18. Iwata H, Kodama I, Suzuki R, Kamiya K, Toyama J. Effects of long-term oral administration on the ventricular repolarization of rabbit hearts. Jpn Circ J 1996 (in press)

19. Mason JW, Hondeghem LM, Katzung BG. Block of inactivated sodium channels and depolarizationinduced automaticity in guinea pig papillary muscles by amiodarone. Circ Res 1984; 55: 277-85.

20. Anderson KP, Walker R, Dustman T, et al. Rate-related electrophysiologic effects of long-term administration of amiodarone on canine ventricular myocardium in vivo. Circulation 1989; 79: 948-58.

21. Epstein LM, Scheinman MM, Chin MC, Katzung BG. The use-dependent effects of acute and chronic amiodarone administration on His-Purkinje conduction and the interaction of beta-adrenergic stimulation. J Cardiovasc Electrophysiol 1991; 2: 156-67.

22. Gallagher JD, Bianchi J, Gessman LJ. A comparison of the electrophysiologic effects of acute and chronic amiodarone administration on canine Purkinje fibers. J Cardiovasc Pharmacol 1989; 13: 7239 .

23. Kamiya K, ChengJ, Kodama I, Toyama J. Modulation of repolarizing potassium channels and Kvl.5 mRNA by long-term treatment with amiodarone. Circulation 1995; 92 (SI): 373.

24. Matsubara H, Suzuki J, Inada M. Shaker-related potassium channel, Kvl.4, mRNA regulation in cultured rat heart myocytes and differential expression of Kv1.4 and Kv1.5 genes in myocardial development and hypertrophy. J Clin Invest 1993; 92: 1659-66.

25. Roberds SL, Knoth KM, Po S, et al. Molecular biology of the voltage-gated potassium channels of the cardiovascular system. J Cardiovasc Electrophysiol 1993; 4: 68-80. 